\title{
Separation and characterization of pentacarboxylic porphyrinogen isomers by high-performance liquid chromatography with electrochemical detection
}

\author{
Famei LI, Chang Kee LIM* and Timothy J. PETERS \\ Division of Clinical Cell Biology, M.R.C. Clinical Research Centre, Watford Road, Harrow, Middx. HA1 3UJ, U.K.
}

\begin{abstract}
A reversed-phase h.p.l.c. system is described for the separation of all five naturally occurring pentacarboxylic porphyrinogen isomers. The compounds are detected electrochemically with high sensitivity. The peaks are positively identified by h.p.l.c. analysis of the pentacarboxylic porphyrinogens from reduction of pentacarboxylic porphyrins prepared by partial decarboxylation of hexa- and hepta-carboxylic porphyrin III of known structures. The resolution of pentacarboxylic porphyrinogens is superior to that of the porphyrins and the method is applicable to the small-scale preparative isolation of pure isomers.
\end{abstract}

\section{INTRODUCTION}

The pentacarboxylic porphyrinogens (Fig. 1) are the ultimate intermediates in the decarboxylation of uroporphyrinogens to coproporphyrinogens (Jackson et al., 1976; Koopmann et al., 1986) catalysed by uroporphyrinogen decarboxylase (EC 4.1.1.37). The accurate analysis, isolation and characterization of these isomers is important for understanding the nature of the stepwise enzymic decarboxylation processes, where pure compounds and positive identification are essential. Although pentacarboxylic porphyrins have been partially separated as methyl esters (Smith et al., 1980) and as free acids (Lim et al., 1983) by h.p.l.c., the separation of pentacarboxylic porphyrinogen isomers has not been reported. The present paper describes the complete resolution of the naturally occurring pentacarboxylic porphyrinogen isomers by reversed-phase h.p.l.c. The porphyrinogens were detected electrochemically with high sensitivity. A simple procedure, based on partial decarboxylation of hepta- and hexacarboxylic porphyrins to pentacarboxylic porphyrins followed by reduction and h.p.l.c. separation of the pentacarboxylic porphyrinogens formed, is developed for the identification of each of the isomers.

\section{EXPERIMENTAL}

\section{Materials and reagents}

Porphyrin methyl ester standards, pentacarboxylic porphyrin I and uroporphyrin III were from Porphyrin Products (Logan, UT, U.S.A.). Ammonium acetate, $15.5 \mathrm{M}$-ammonia (sp.gr. 0.88), acetic acid, $\mathrm{KOH}$, $\mathrm{NaHCO}_{3}$, conc. $\mathrm{HCl}$, conc. $\mathrm{H}_{2} \mathrm{SO}_{4}$, EDTA (disodium

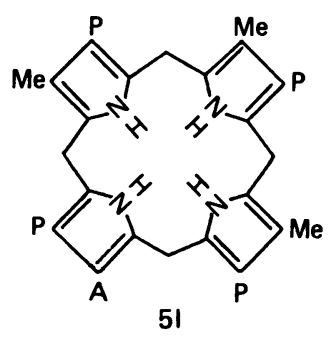

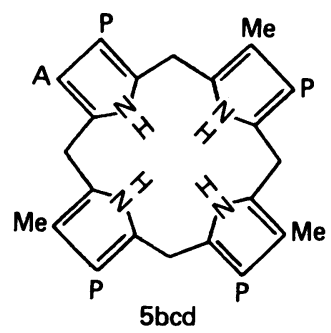

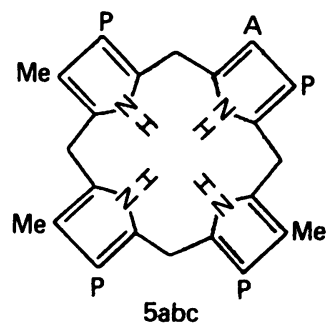

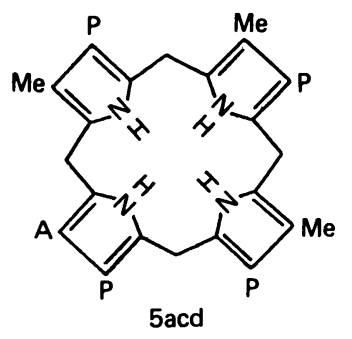

Fig. 1. Structures of pentacarboxylic porphyrinogen isomers<smiles>Cc1ccc(Cc2ccccc2Cc2ccccc2Cc2ccccc2)cc1</smiles>

Isomer $5 \mathrm{I}$ is pentacarboxylic porphyrinogen I. Isomers 5bcd, 5acd, 5abc and 5abd are the type III isomers. The letters a, b, $c$ and d denote the position of methyl groups, i.e. the positions in which the acetic acid groups have been decarboxylated (Jackson et al., 1976). A represents an acetic acid group and $\mathrm{P}$ a propionic acid group.

\footnotetext{
* To whom correspondence and reprint requests should be addressed.
} 
salt), chloroform, dichloromethane, carbon tetrachloride, ethyl acetate and 5\% sodium amalgam were AnalaR grade from BDH Chemicals (Poole, Dorset, U.K.). Methanol was h.p.l.c. grade from Rathburn Chemicals (Walkerburn, Peebleshire, U.K.). Hexachlorobenzene was analytical grade from Aldrich Chemical Co. (Gillingham, Dorset, U.K.).

Isolation of penta-, hexa- and hepta-carboxylic porphyrins from faeces of rats treated with hexachlorobenzene

Female Sprague-Dawley rats were fed with powdered laboratory chow mixed with $0.2 \%(\mathrm{w} / \mathrm{v})$ hexachlorobenzene for 6 weeks. After completion of the treatment faeces were collected daily for 2 weeks.

Faeces $(5 \mathrm{~g})$ were dispersed thoroughly in $100 \mathrm{ml}$ of methanol/conc. $\mathrm{H}_{2} \mathrm{SO}_{4}(19: 1, \mathrm{v} / \mathrm{v})$ and refluxed for $10 \mathrm{~min}$ at $60^{\circ} \mathrm{C}$. The mixture was filtered and the residue was washed with $10 \mathrm{ml}$ of methanol/conc. $\mathrm{H}_{2} \mathrm{SO}_{4}(19: 1, \mathrm{v} / \mathrm{v})$ and again filtered. The combined filtrate was poured into a separating funnel containing $50 \mathrm{ml}$ of chloroform. Then $300 \mathrm{ml}$ of water was added and the mixture was shaken vigorously and allowed to settle. The chloroform layer was collected and the aqueous solution was extracted with a further $10 \mathrm{ml}$ of chloroform. The combined extract was washed successively with $200 \mathrm{ml}$ of saturated $\mathrm{NaHCO}_{3}$ solution and twice with $150 \mathrm{ml}$ of water. The organic layer was then filtered through a filter paper (Whatman no. 1) pre-wetted with chloroform, and the filtrate was evaporated to dryness at $50^{\circ} \mathrm{C}$ under reduced pressure. The residue was redissolved in $1 \mathrm{ml}$ of chloroform, and $100 \mu 1$ portions were loaded with a Chromatocharger (Camag, Muttenz, Switzerland) on to $20 \mathrm{~cm} \times 20 \mathrm{~cm}$ silica gel $\mathrm{G}(250 \mu \mathrm{m}$-thick) t.l.c. plates (Analtech, Newark, DE, U.S.A.). The developing solvent was dichloromethane/carbon tetrachloride/ethyl acetate $(1: 1: 1$, by vol.) A standard mixture of porphyrin methyl esters was used to locate the individual porphyrins, which were well separated by this system. The bands corresponding to penta-, hexa- and hepta-carboxylic porphyrin methyl esters were collected. The methyl esters were then hydrolysed for $72 \mathrm{~h}$ in $25 \%$ (w/v) $\mathrm{HCl}$ at room temperature in the dark.

Preparation of pentacarboxylic acid porphyrin III isomers by partial decarboxylation of uroporphyrin III and heptacarboxylic and hexacarboxylic porphyrin III

The porphyrin (uroporphyrin or heptacarboxylic or hexacarboxylic porphyrin) in $5 \mathrm{ml}$ of $0.3 \mathrm{M}-\mathrm{HCl}$ in a Pyrex tube was thoroughly flushed with $\mathrm{N}_{2}$ and capped. The solution was heated for $1 \mathrm{~h}$ at $150^{\circ} \mathrm{C}$ in the dark. After cooling, $30 \mathrm{ml}$ of methanol/conc. $\mathrm{H}_{2} \mathrm{SO}_{4}$ (19:1, $\mathrm{v} / \mathrm{v}$ ) was added and the mixture was refluxed for $10 \mathrm{~min}$ at $60^{\circ} \mathrm{C}$. The resulting porphyrin methyl esters were purified by preparative t.l.c. The pentacarboxylic porphyrin ester band was collected and hydrolysed to the free acid as described above. The partial decarboxylation of uroporphyrin III produced all four type III pentacarboxylic porphyrin isomers. This was used to prepare the type III pentacarboxylic porphyrinogen standard solution.

\section{Preparation of pentacarboxylic porphyrinogens}

The porphyrins were dissolved in $250 \mu \mathrm{l}$ of $0.01 \mathrm{M}-\mathrm{KOH}$, and the solution was shaken vigorously with $5 \%$ sodium amalgam until no fluorescence was detectable under a u.v. lamp. The porphyrinogen solution was transferred into a clean vial, flushed with $\mathrm{N}_{2}$ and capped. It was stable for at least $3 \mathrm{~h}$ when kept on ice in the dark. Acid solutions of pentacarboxylic porphyrins were adjusted to $\mathrm{pH} 3.8-4.0$ with aq. $\mathrm{NH}_{3}$ and extracted into ethyl acetate, which was then removed by vacuum evaporation at $50^{\circ} \mathrm{C}$. The residue was redissolved in $0.01 \mathrm{M}-\mathrm{KOH}$ and reduced with $5 \%$ sodium amalgam.

\section{H.p.l.c. of pentacarboxylic porphyrinogens}

A Varian Associates (Walnut Creek, CA, U.S.A.) model 5000 liquid chromatograph was used. Injection was via a Rheodyne (Cotati, CA, U.S.A.) 7125 injector fitted with a $100 \mu l$ loop. The separation was carried out on a $25 \mathrm{~cm} \times 5 \mathrm{~mm}$ ODS-Hypersil ( $5 \mu \mathrm{m}$-particle-size) column (Shandon Southern, Runcorn, Cheshire, U.K.) with $40 \%(\mathrm{v} / \mathrm{v})$ methanol in $1 \mathrm{M}$-ammonium acetate buffer, pH 5.16, containing 0.27 mM-EDTA as eluent at a flow rate of $1 \mathrm{ml} / \mathrm{min}$. The mobile phase was continuously degassed with a stream of $\mathrm{He}$ during the separation. An LCA-15 electrochemical detector (EDT Research, London N.W.10, U.K.) set at an operating

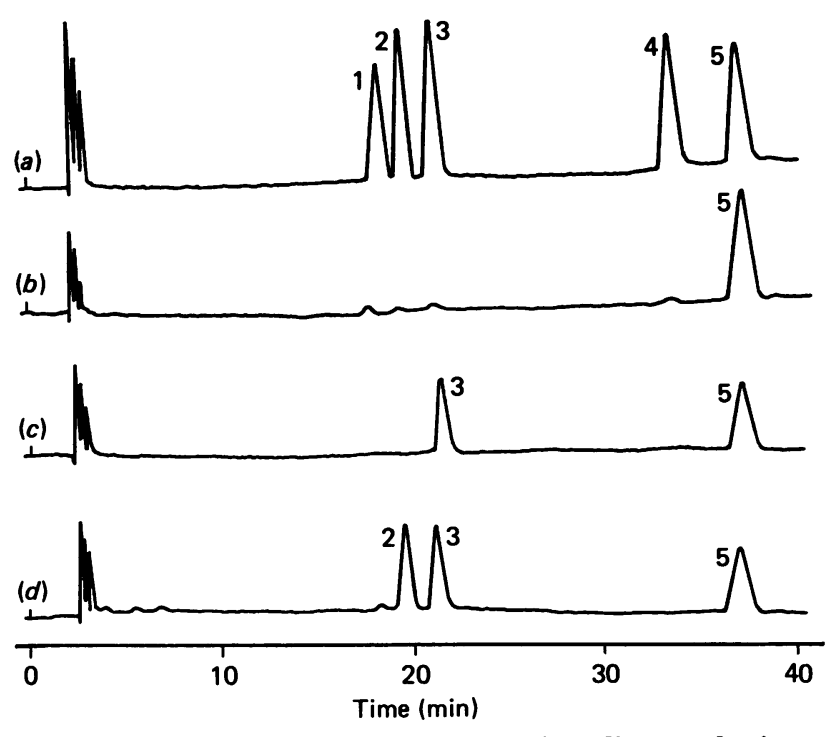

Fig. 2. H.p.l.c. separation of pentacarboxylic porphyrinogen isomers

(a) A standard mixture. (b) Pentacarboxylic porphyrinogen from reduction of pentacarboxylic porphyrin with the acetic acid groups at rings $\mathrm{A}, \mathrm{B}$ and $\mathrm{D}$ decarboxylated. (c) Pentacarboxylic porphyrinogens from reduction of pentacarboxylic porphyrins prepared by partial decarboxylation of hexacarboxylic porphyrin III with the ring A and D acetic acid groups decarboxylated. (d) Pentacarboxylic porphyrinogens formed by partial decarboxylation of heptacarboxylic porphyrin III with the ring $D$ acetic acid group decarboxylated. The porphyrins in $(b),(c)$ and $(d)$ were isolated from faeces of hexachlorobenzene-treated rats. The separation was carried out on a $25 \mathrm{~cm} \times 5 \mathrm{~mm}$ ODS-Hypersil ( $5 \mu \mathrm{m}$-particle-size) column with $40 \%$ (v/v)

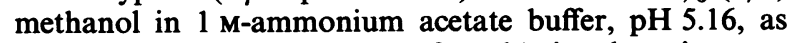
mobile phase, at a flow rate of $1 \mathrm{ml} / \mathrm{min}$; detection was amperometric at $0.70 \mathrm{~V}$. Peak 1 , isomer $5 \mathrm{I}$; peak 2, isomer 5bcd; peak 3, isomer 5acd; peak 4, isomer 5abc; peak 5, isomer 5abd (see Fig. 1). 
potential of $0.70 \mathrm{~V}$ with a detector sensitivity of $30 \mathrm{nA}$ was used for solute detection. For small-scale preparative separation a u.v. detector set at $240 \mathrm{~nm}$ was employed.

\section{RESULTS AND DISCUSSION}

The separation of a standard mixture of type I (5I) and the four type III (5abd, 5acd, 5abc and 5bcd) pentacarboxylic porphyrinogen isomers is shown in Fig. 2(a). Isomer 5I (peak 1) can be easily identified because a pure standard is available commercially. Jackson $e t$ al. (1976) have shown by n.m.r. and chemical synthesis that the pentacarboxylic porphyrin III isolated from the faeces of hexachlorobenzene-treated rats was the one with the acetic acid groups at rings A, B and D decarboxylated. We have purified this compound by h.p.l.c. with the system previously described (Lim et al., 1983) and have confirmed their observation by similar n.m.r. analysis. This porphyrin gave peak 5 (Fig. $2 b$ ) on reduction. Peak 5 is thus unequivocally assigned as isomer 5abd.

Jackson et al. (1976) have further shown that the heptaand hexa-carboxylic porphyrin III isolated from the faeces of hexachlorobenzene-treated rats were almost entirely the isomers with the ring $D$ and ring $A$ and $D$ acetic acid groups decarboxylated respectively. These two compounds are ideal starting materials for the positive identification of the other three pentacarboxylic porphyrinogen isomers by partial decarboxylation, sodium amalgam reduction and h.p.l.c. separation.

The partial decarboxylation of hexacarboxylic porphyrin III with the ring A and D acetic acid groups decarboxylated can only produce two type III pentacarboxylic porphyrin isomers, that with the ring A, B and $D$ acetic acid groups decarboxylated and that with ring A, C and D acetic acid groups decarboxylated. Sodium amalgam reduction followed by h.p.l.c. separation gave peaks 3 and 5 (Fig. 2c). Since peak 5 is isomer 5abd, peak 3 is therefore isomer 5acd.

Three pentacarboxylic porphyrin III isomers are formed by partial decarboxylation of a heptacarboxylic porphyrin. The heptacarboxylic porphyrin III with the ring D acetic acid group decarboxylated can only produce isomers with the ring $\mathrm{A}, \mathrm{B}$ and $\mathrm{D}$ acetic acid groups, ring $\mathrm{A}, \mathrm{C}$ and $\mathrm{D}$ acetic acid groups and ring $\mathrm{B}$, $\mathrm{C}$ and $\mathrm{D}$ acetic acid groups decarboxylated. H.p.l.c. analysis of the corresponding pentacarboxylic porphyrinogens gave peaks 2, 3 and 5 (Fig. 2d). Peaks 3 and 5 have already been identified as isomers 5acd and 5abd respectively. Peak 2 is therefore isomer $5 \mathrm{bcd}$, and peak 4 , the remaining peak, must be isomer 5abc.

The final confirmation of peak identity was obtained by small-scale preparative h.p.l.c. isolation of each isomer. The purified porphyrinogen was reconverted into the corresponding porphyrin by oxidation under light illumination. The identity of the isomer was then confirmed with the established h.p.l.c. method for characterization of porphyrin isomers (Lim et al., 1983).

The resolution of pentacarboxylic porphyrinogen isomers was superior to that of the porphyrins by reversed-phase chromatography. This is similar to previously obtained results on the separation of coproporphyrinogen isomers (Lim et al., 1986). The separation of porphyrinogens is therefore preferred for the analysis of isomers important in biochemical studies. The better resolution also allows pure isomers to be isolated from chemical synthesis and from biological materials.

We are grateful to the Department of Education, People's Republic of China, and The British Council for financial support (to F. L.).

\section{REFERENCES}

Jackson, A. H., Sancovich, H. A, Ferramola, A. M., Evans, N., Games, D. G., Matlin, S. A., Elder, G. H. \& Smith, S. G. (1976) Philos. Trans. R. Soc. London Ser. B 273, 191-206

Koopmann, G. E., Juknat de Geralnik, A. A. \& Batlle, A. M. del C. (1986) Int. J. Biochem. 18, 935-944

Lim, C. K., Rideout, J. M. \& Wright, D. J. (1983) J. Chromatogr. 282, 629-641

Lim, C. K., Li, F. \& Peters, T. J. (1986) Biochem. J. 234, 629-633

Smith, S. G., Rao, K. R. N. \& Jackson, A. H. (1980) Int. J. Biochem. 12, 1081-1084 